\title{
Systems Psyche: Its Structure, Operation and Possible Molecular Links Mukhopadhyay $\mathrm{AK}^{*}$
}

All India Institute of Medical Sciences, New Delhi

\begin{abstract}
The psyche stands, connects and operates in between consciousness and matter. Traditionally, the psyche has been considered to have a monolithic structure composed of mind or consciousness. From a robust common sense experience and from the experience of those engaged in inward Olympics with mind this paper theoretically dissects the constituent member of the psyche and their autonomous operations and interaction. From the insight of its polylithic character the paper develops a new description of Systems Psyche. Sandwiched between consciousness and matter the model comprises of a complex relational matrix, a stratified, hierarchically nested labyrinthine structure and process. The probable footprints of the operations at molecular synaptic level have been suggested, which merit further research for developing a concrete picture. These molecular connections could emerge as the basis of developing a systems science accommodating systems biology with systems psychology while consciousness remains active at the top. A beneficial spin off is a new way of classifying psychological and psychiatric disorders.
\end{abstract}

Keywords: Consciousness; Monolithic structure; Psycho dynamics; Embryonic psyche

\section{Introduction}

The psyche, the decision making organic apparatus, is the essence of the being. Top-down, the somatic dynamics (behavior) is determined essentially by psycho dynamics. In reverse, bottom-up, the bodily dynamics influences the state of the psyche. The psyche evolves with time. The process of evolution of embryonic psyche to its mature adulthood form may be called its ontogeny, which recapitulates the entire phylogeny in its entire development. The evolution of Homo sapiens to some new species, something more complex, something remarkably better, often called Homo spiritualis, is essentially a psychic evolution. Psyche is the conveyer of the Spirit (unconditional consciousness) to the somatic systems and is the conduit of the somatic body to the spirit world. Psyche is the nature of consciousness and this nature is in dynamic communication with nature investigated in physical science. Psycho-spiritual and psychosomatic are therefore two facets of the same coin. The question is, what is this coin? What it is made of? How this non-physical entity connects the 'physical' with the 'spiritual'? Do we have any model of it or its dynamics?

The traditional model of the psyche consists of mind or consciousness, even without having a clear distinction between the two. The possessor of the psyche, the lord of the psyche, the 'self, has not been given credible position in this model. The relationship between information and mind has not been deciphered. So is also between mind and self. Is the organ psyche a property of only living organism? If so, what is its relationship with 'life'? On the backdrop of such plethora of questions, over last few decades there is an enormous input of knowledge from empirical analytical phenomenology (for example, on the role of self) and transpersonal psychology (for examples, non-locality and trans-temporality of mind, out-of-body experiences, autoscopy etc.). The varieties of psychedelic and spiritual experiences have contributed to the complexity in the knowledge of psyche. Cognitive neuroscience has emerged as one of the frontier disciplines. Molecular biology, genomics and epigenomics of dementia have been under serious investigation. The discipline of psychoneuro-immunology has been flourishing. The neuroscience has been looking for the neural fabrics of mind and the cell biologists have been searching for mind within the cell. Evidence for cellular cognition suggested an existing bond between psyche and life without any role of the brain. Even in physical science particularly in quantum physics, the role of consciousness in observation and measurement has been recognized and whether this is due to influence of mind, self or consciousness of the observer is yet to be decided. In addition, the computer science has taken over the information processing function of mind with unimaginable speed and flawlessness while the discipline of robotics has been taking over miniscule of the functions of 'self' and intelligence associated with it. The attempts of "mind-uploading" on signal network or global sensor have brought physical scientists closer to human psyche.

Doesn't this scientifically charged emerging milieu call for a new comprehensive model of the psyche that can withstand, incorporate and assimilate these new inputs of evidence-based knowledge in the open market of scientific research? We are challenged with the question, what is this non-physical psyche that is being dealt with in psychological science? Are all events in the inner world of us run by the ghost(s) in the machine (brain)? If psyche is organic, what could be its operational mechanics like? How does the psyche do multidimensional multitasking, although not completely free of any error? Is the psyche made up of really only one stone, as a monolith? Or, does it have a polylithic structure with multiple operations and operators? Is it possible to develop a systems science with the constituents of psyche? And next, is it possible to place the systems psyche within the systems biology? How the systems psyche could be connected with the science of consciousness? Where in the psyche do the ultimate motivational factors work? This paper addresses some of these questions and builds up a new definition and description of the psyche as systems. It dissects out the fundamental elementary member of the psyche, examines their individual and collective operations and develops a structured model on the basis of its operators' relational matrix. The proposed model retains

*Corresponding author: Mukhopadhyay AK, All India Institute of Medical Sciences, New Delhi, India, Tel: 011-26589999; E-mail: mukhoak1953@gmail.com

Received May 31, 2016; Accepted July 28, 2016; Published August 05, 2016

Citation: Mukhopadhyay AK (2016) Systems Psyche: Its Structure, Operation and Possible Molecular Links. Abnorm Behav Psychol 2: 121. doi: 10.4172/24720496.1000121

Copyright: (c) 2016 Mukhopadhyay AK. This is an open-access article distributed under the terms of the Creative Commons Attribution License, which permits unrestricted use, distribution, and reproduction in any medium, provided the original author and source are credited. 
the core scientific identity and rigor of the discipline of Psychology and Psychiatry. Deeply rooted into the primacy of consciousness the proposed model places psyche within the systems science as a whole, without reducing anything and excluding almost nothing available in the knowledge systems.

\section{The Psyche: The Renaissance in its Recent Conceptual Understanding}

The definition of the psyche as given in wikipedia, ranges from the mind to angel to eros and the spirit. The psyche has long been considered monolithic, composed of mind or consciousness. Even when a neuroscientist of Sir John C. Eccles' status transcends materialism and enters the domain of non-physical psyche, he proposes hypothetical existence of the unit of psyche, the "psychon", a unit for mental activity in his work [1]. There is no further analysis of whether this non-physical unit really indivisible? Or, does it have several components?

Let us look and examine the usual responses from several educated medical doctors, on the question what is meant by the psyche! "The psyche is mind!" "The psyche is feelings!" "The psyche is consciousness!" "The psyche is self!" "The psyche is the epiphenomenon in information processing system within the brain!" "The psyche is the condensed 'life' of the individual!" "The psyche is the 'soul'!" All these responses seem right, but incomplete since each of these descriptions is only on one facet or one fundamental aspect of the psyche. When all the responses are considered together into one unified account, the psyche does not appear as structurally monolithic. The comprehensive image of the psyche appears polylithic in structure consisting of several ontological entities like Consciousness, Mind, 'Self, 'Life' and Information, each having its specific epistemological processes. There are five distinct pieces that constitute the whole puzzle. This conceptualization has concurrence with the experience of millions of practitioners engaged in yoga and meditation, an inward Olympics with this puzzle of consciousness.

None of these ontological entities as mentioned above is either physical or localizable. All of them are, however, organic and having intention and therefore contribute towards causality. Our brain could be considered their 'home', for their lodging, boarding and operations. There are natural scientists who trace the existence and function of the psyche to plants, brain-less worms, unicellular organisms such as bacteria [2], genes, and even into the deeper recess of nature. Michael Pollan [3] in his books The Omnivore's Dilemma [3] and The Botany of Desire [4] addresses the issues like whether the plant can sense, learn, remember and even react in ways that would be familiar to humans! Several Astrophysicists invoke 'mind' in deeper recess of nature. For example, Roger Penrose in The Emperor's New Mind [5] and Stephen Hawking saying, "Mind of God is at the boundary of the universe", and Max Tegmark [6] finding some structure in Multiverse level IV, which can mindfully operate. As early as 1987, the author [7] wrote a chapter on Psychology of a Cell in his book The Dynamic web of Supracortical Consciousness. In 2011, there is a book available, titled Geneopsych [8], relating primary instincts of all living organisms to primary properties of DNA molecules.

It seems that wherever a defined and integral conglomeration of consciousness, mind, self, life and information could be identified it is possible to locate there and identify an operational mechanics of the psyche. This new development differs from well-known and old panpsychism, where in everything and in everywhere there is mind (or consciousness). In contrast to panpsychism, the new emerging model of the psyche is discrete in nature. This property of discreteness comes from its polylithic nature with constituent like 'self. Unlike, consciousness, life and mind or even information, self could not be found everywhere, even by panpsychist! Self is discrete and is the representative of consciousness within a self-organizing system. This fact raises the possibility of developing a systems science of psyche. The model of the psyche proposed here is organic, polylithic and is an everopen complex syncitium of five ontological entities with their defined epistemological processes. It could be brain-confined as well as brainindependent.

\section{Why Polylithic Structures Appear as Monolithic?}

The psyche in spite of having a polylithic structure appears and operates as monolith as evident from its unified behavioral response. Physiologically it responds with unity as a whole, as if functionally it is one. We would be seeing that all of the constituents of the psyche have individual operation and together they have a collective operation. Collective operation in unity makes psyche appear as monolith. The closest biological simile, which can be cited to understand the essence of this polylithic-monolithic debate, is a cell-syncitium where all the constituent cells of the syncitium act in unison for the purpose it is meant for (e.g. myocardium). More simply, an unicellular organism or a cell with constituents of several organelle like nucleus, mitochondria, lysosome, Golgi apparatus etc. enclosed within a cell membrane responds as one, in unity, despite different organelles have been continuing their independent operation with autonomy. All operate within the ambit of oneness of the whole. That the psyche is structurally polylithic but output-wise (i.e., functionally) monolithic in its physiological state could be the description nearest to its true nature.

\section{Characteristic of the Science of Psyche}

None of consciousness, mind, self and life could be objectively observed, reduced, or measured even within Planck's scale of nature, $10^{-32} \mathrm{~cm}$, Planck's length and $10^{-43} \mathrm{sec}$, Planck's time. Therefore, unlike the physical science, the science of the psyche could not be objective, reductivistic or positivistic. Also, contrary to the claim of several pragmatic quantum physicists, the psyche is not amenable to quantum physics. It is because the psyche operates from beyond the Planck's scale of nature. On the other hand the reported shift $[9,10]$ of several constants established by Max Planck, might be explained by the enhanced cognitive ability (psychic ability) due to continued evolution of the human psyche and the brain.

All the constituent entities of the psyche are non-local in nature, meaning they could not be localized in space or in time, neither within the brain nor outside the brain! This is unlike the local players in physical science such as Time, Space, Matter and Energy. It is Information, which could be present inside both matter (for example, in silicon chip) and mind (mind is information-hub). It is information, which builds the bridge between the players at nonlocal and local domain of nature (Figure 1).

The science of the psyche, even now, operates on inter-subjective agreement between the specialists at appropriate level. The psyche is never examined in a reduced state. Measurement of a parameter in this discipline is adopted on mutually agreed defined scales. The key or the thread to the science of this nonlocal domain is the science of information. The operations of the psyche, although, are carried out beyond the measurable scale of nature, their footprints are predicted to be identified within observable measurable nature with signature signal and signature molecule of its constituents. This is a great task ahead.

As there are electro-magnetic field, gravitational field, quantum 


\begin{tabular}{|c|c|c|c|c|c|}
\hline Consciousness & $\begin{array}{c}\text { "Entities" involved in } \\
\text { Nonlocal Science }\end{array}$ \\
Information & \\
\hline Matter, Energy & "Entities" involved in \\
Time, Space & Local Science
\end{tabular}

Figure 1: Constituents of "Local" and "Non-local" science.

field etc., in the physical world, so in the nonlocal domain all the members of the psyche is proposed to have their respective 'field' like mind-field, consciousness-field, information field or the psychic field as a whole.

\section{Identification of the Constituents of the Systems Psyche and their Operations}

According to this proposition, consciousness, mind, self, life and information together constitute [11] the systems psyche. All are "non-observable Influential(s) in the domain of consciousness". These 'influential's, either as ontological entities or as defined epistemological processes, exist in phase with formation of a syncitium-like structure and operate from sub-Planckian scale of space, time and energy. The mystic often glimpses them as independent 'moment' of experience, which the mind of scientist considers as individual dimensionless point (or often as a 'string' when construed within Planck's scale). The constituents of the psyche could be identified by their operation. Each of the constituents has an operational mechanics of their own and an interactive mechanics as a "syncitium".

\section{Operations of mind}

Mind could be identified by its operation as an organ of communication between two conscious systems. Mind originates in duality. There is no room for mind in material or consciousness monism. Mind does not have independent existence. It always exists with two conscious systems. As there are layers of consciousness, so there are layers of mind in between (c.f., Sri Aurobindo's classification: ordinary mind, over mind, intuitive mind, illumined mind and supermind existing in between different levels of being consciousness). The mind is the signal-information interface. Inter-conversion of signal and information is done by mind. By nature, the mind is sensitive to and responds to informational input. Mind processes, sorts out and prioritizes information as programmed by self. Mind retains the memory of information as semantic memory. For its service, mind reports to 'self.

While consciousness never looks back, the mind always operates on the basis of its past 'energy' loaded in the experience and in memory. While consciousness refreshingly unites, the operation of mind divides. Mind bereft of consciousness is, however, sterile. Fecundity of mind is due to its connection with consciousness while infidelity is gained because of its association with matter. The strength of mind comes from its association with "life". Mind's ability to discriminate, judge and decide is derived from "self". Mind's own and borrowed properties are shown in Figure 2.

Mind can also act as internal sense organ. Being independent of five senses it can access information directly, conceives it and can make information's inside out, thus delivering form (space and time) and energy. The 'form' (as 'thought') is a construction of space-time, and the energy released is information-based energy (in contrast to familiar matter-based energy). This phenomenon has been described as "information split". In folk language, information is the 'father', mind is the 'mother', while space, time and energy are their three children.

Importance of operation of mind: We do not work with our consciousness. We work with our mind (and intellect). It is mind, which connects all of consciousness, self and 'life' with matter. In absence of mind there is no connection of us (our consciousness) with what we call physical. Direct connection with consciousness makes sterile mind fertile. Direct connection with matter makes mind an infidel character.

Beside its direct continuity with consciousness, mind is also connected with consciousness via 'life' and through 'self. The communication between consciousness and self, and between consciousness and 'life', are not carried out by any kind of information. This communication is more intangible than that carried out by information. Mind is connected with the matter through information mechanics. Mind creates space and time and therefore creates multiple dimensions out of information.

\section{Operations of the self}

Consciousness appoints 'self' as its chief executive officer (CEO) within the system to cognize, to experience and feel, and carry out the will of consciousness. Therefore, the self is conditioned by information to function within constrains inherent in the system. Self is also responsible for keeping the system 'open' to unconditional consciousness. The decision-making authority within the system is 'self. Self does conditioning and programming of mind to process information. Self retains the memory of episodic experience. On the background of experience (memory), self creates with mind what is called Intelligence. With the participating consciousness, in conjunction with operations of "life", the operation of self is responsible for awakening, self-awareness and choice. Self is sensitive to phenomena and responds accordingly. Figure 3 shows eight contributions of 'self towards operation of the psyche.

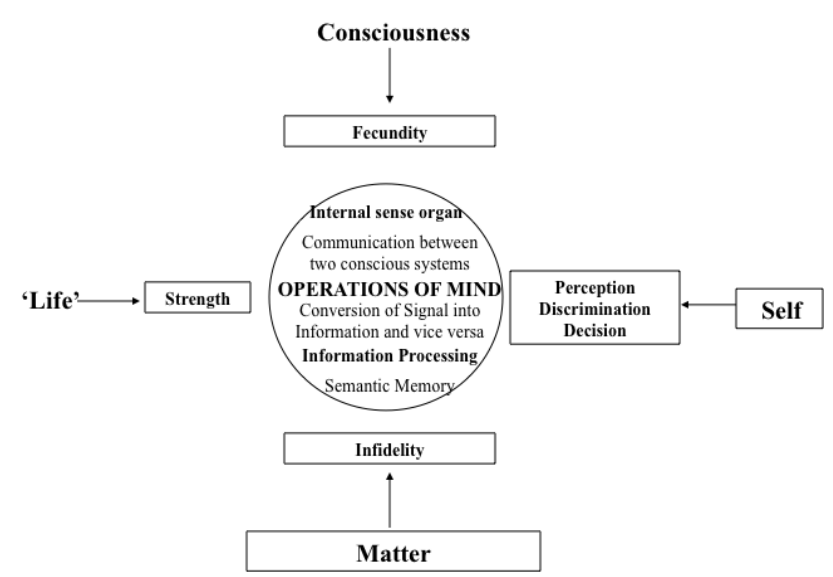

Figure 2: Mind's 'own' (within circle) and 'borrowed' (within rectangle) properties. 


\section{Operation of "Life"}

All self-organizing systems in nature are not alive and therefore, cannot demonstrate the full operation of the psyche. 'Life' is an important constituent of the psyche. The psyche could be found in a system where life has flourished. In dead subject no one looks for psyche. If mind transforms signal into information, it is 'life' which transforms information into knowledge. Information is digital (Shannonian). Knowledge is non-digital (Godelian). Creation of knowledge and organization of knowledge are functions of 'life'. However, 'life' means differently to different discipline. It is 'life-form' to a biologist, 'living state of matter' to a material scientist and life-principle or elan vital, to an accomplished spiritualist. The details of what one can understand by life-principle, life-form and living state of matter is available in author's paper titled, "Life within the Akhanda Worldview" [12].

"Life", as an ontological entity could be called the "principles of life" [13] for scientific vocabulary. The source of 'life' is life only. 'Life' comes from life ("Omne vivum e vivo." - Louis Pasteur). This principle, as the non-local operator of "life", is sensitive to alteration/ change in the symmetry of the system. Its operational response too is aimed at restoring the symmetry. The 'life' thus operates for healing, which means to bring the system in harmony with the whole. Life has access to dark energy. Of all the elements of the psyche, only 'life' has the ability to participate in total energy homeostasis overarching both

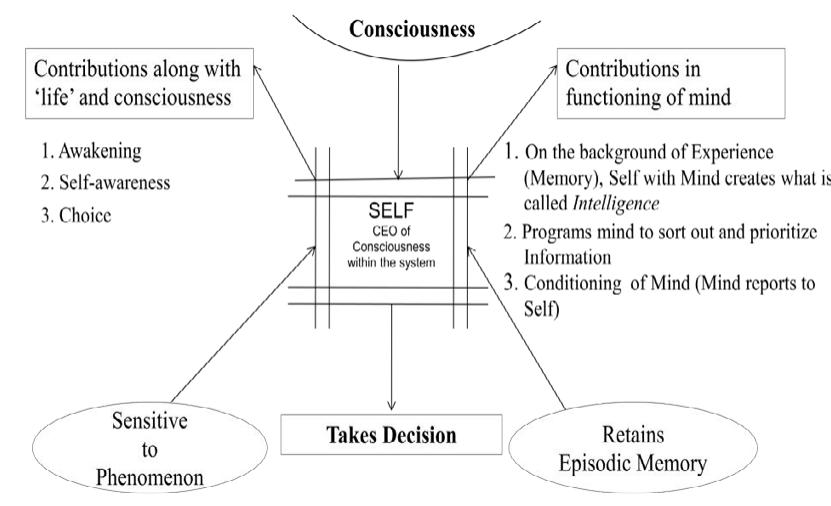

Figure 3: Eight operations of self; two are of its own to take decision and to retain episodic memory; three each along with mind, and life and consciousness. dark energy and conventional energy. Probably because of this, 'life' can confront and withstand uncertainty. Total nine operations of 'life' have been shown in Figure 4. Three operations are of its own. Three are contributions towards function of mind. Three are joint operation of life, self and consciousness.

\section{Operation of information}

The psyche is certainly an information hub. The nature of physical cosmos and the nature of psyche remain interconnected through information. It is through the operational mechanics of information the mind remains open to matter! The source-field of information is 'life'. No information-as-such, however, could reach consciousnessas-such! The author takes a radical view of information, on its nature and science [14], where information is as abstract as an entity in phase beyond Planck's scale of nature. The so-called information written on this paper or in a spoken language is a space-time construction that is read as information only by mind. Regarding the operational mechanics of information, the following quote from author's already published paper [15] seems relevant.

"Information has a mechanics of its own. Information mechanics is a mechanics of waiting. Information for its manifestation could wait for eons, for millions of years. Waiting is mostly attributed to inactivated form of information". Waiting is a courageous skill for conquering the life's tempest. "Activation opens up its opportunistic property. Information mechanics is a mechanics of opportunism. Information is opportunistic. Therefore, imperatively, it is slow, patient, and intelligent. Its dynamics are nonlinear. (The process of evolution is also considered an opportunistic one; probably in the process of evolution intertwined is the information mechanics). Information, in opportune moments, asserts causal execution. Information works as the causal executive. The system undergoes changes according to input, output, or re-assortment of information within. Informational link, therefore, represents the causal link. Information loss explains the break in the causality chain. Information mechanics is also responsible for what we observe as creative emergence. Information reorganizes space and time bringing a new meaning and a new context. Finally, the mechanics of new creation is inextricably connected with the mechanics by which a new "form," a new space-time organization, comes out of information!"

"In the pre-space, pre-time domain, information waits patiently

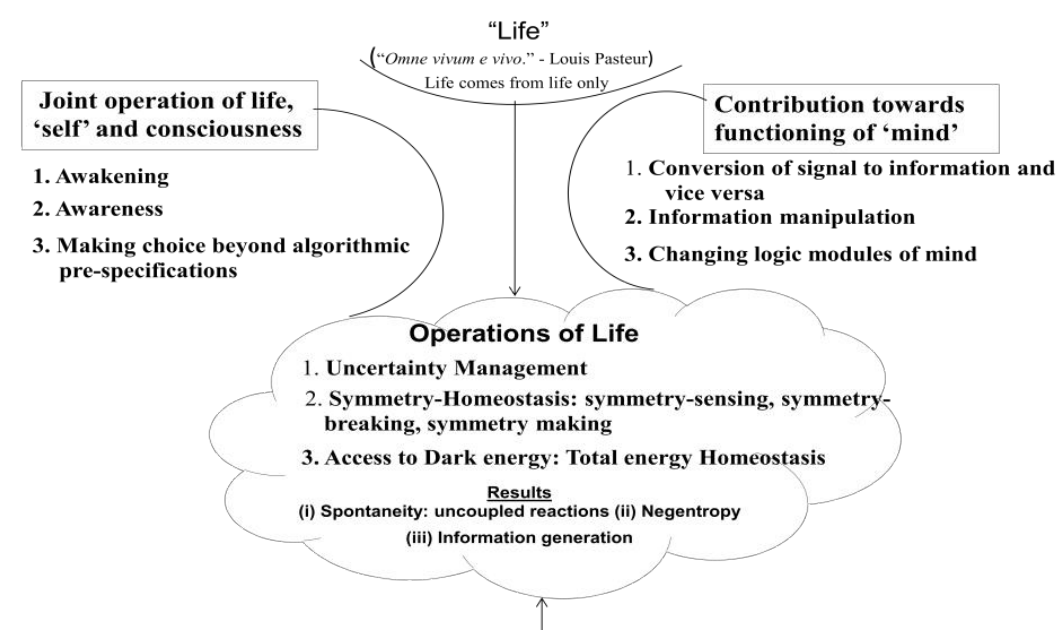

Figure 4: Nine operations of life; three are 'solo', three are co-contribution towards operations of mind and three are joint operation of self, life and consciousness. mind, and life and consciousness. 
and intelligently to get carried on the vehicle of a "quantum" and looks forward to getting accepted in a receptive system where it can perform causal execution, or can bring about creative emergence. The most creative function of information is displayed when it takes the opportunity to impregnate a prepared and receptive mind, or mind-like structure and process in nature. This results in delivery of new space, new time, and the information-based intrinsic energy of quietude".

Inactive information is bipolar, spindle-shaped. Active information is like a trifoliate leaf [15]; its measurable folium interacts with signal network of material plane, its content folium interacts with logic modules in mind and its intent folium interacts with global sensor of the 'self. Information thus in its activated form connects matter, mind and self (Figure 5).

How signal is transformed into information?: Transformation of signal into information is done inside the mind. However, the process involves all other constituents of the psyche. Signal is physical, specific space-time geometry, a kind of 'form', a specific dimension or design of space and time. Since all are combination of space and time, those are amenable to our senses. This forms the observable and measurable folium of information. Within the systems having a psyche, this sensible form is aided within mind with an intention from consciousness. Self handles this intent of consciousness within the system and builds up a sensor for the intent to work within it. With this intention, self-chalks out modules of logic from the space-time contents and hands over this logic modules to mind as what we call program. Thus, the entity acquires a trifoliate structure with system's self-having its intent sensor, mind having its logic program and spacetime form remains in the matter in the physical plane. This trifoliate structure is unstable in life-less system. The stability is brought when the petiole of the trifoliate structure, gets nourishment from 'life'. Life offers this nourishment from an unusual source, the dark energy (which constitutes approximately $70 \%$ of our universe)! Dark energy is consumed during transformation of signal into information.

How information is transformed into signal?: Information resides within the psyche. Signal, the physical construct from information is in the material plane. This transformation happens inside mind, which releases dark energy during transformation. Homeostasis of this released energy is made possible by 'life'.

\section{Operations of consciousness}

Consciousness is difficult to define. The term can be used in generic sense or as ground. Whether generic or ground, consciousness maintains its own absolute independence. Like a spider, consciousness weaves the net but itself is outside the snare of the net. It remains as a non-negotiable imperative. Consciousness does not bow down to anyone. It kowtows to none. Consciousness acts as both supporting and participating ground. As a supporting ground, consciousness holds all together. In an unconscious patient, consciousness is not in a functional mode within the system. The mind continues to work (as evident from patient retaining control over his sphincters), information processing goes on, the person is alive, and even the self is functional. However nothing is there to hold all the operations together and to produce a unified behavior. The supporting ground-effect is absent. The subject is functionally invalid! As a participating ground, consciousness looks after what has been going on in mind, self and life within the systems. The objective of its participation is to maintain the order and coherence in the whole game. It maintains autonomy of its constituents and intervenes only in conflict and resolves it.

Consciousness, although, is the final decision-making authority it operates for all practical purpose in silence, stillness, emptiness and nothingness. 'der list der Vernunft', said Georg Wilhelm Hegel. It means, consciousness cleverly conceals itself and denies itself, and by concealing its modus operandi, it advances its own operation.

It is extremely difficult to find out the appropriate stimulus to which consciousness would respond! However, this is certain that consciousness always responds to the process of surrender of properties by any other constituent of the psyche. The recognized operations of consciousness are generation of will, cognition and feelings, and the outcomes respectively are acquisition of skill, knowledge and attitude (Figure 6).

While all of will, cognition and feelings are operational outcomes of consciousness the behavioral manifestation of the systems is largely dependent on the nature of infrastructure within it (brain). The person having adequate infrastructure for execution of 'will' becomes an excellent executive. Infrastructures for cognition make the person a brilliant think-tank. With a strong infrastructure for feelings the individual becomes an involved loyalist. As a rare example, one might become a three-in-one. Education has been defined as which brings a change in the behavior of the learner in terms of knowledge skill and attitude reflecting the output from cognitive, psychomotor and affective function of consciousness. There might be a question on of the three operations of consciousness which one is the most important?

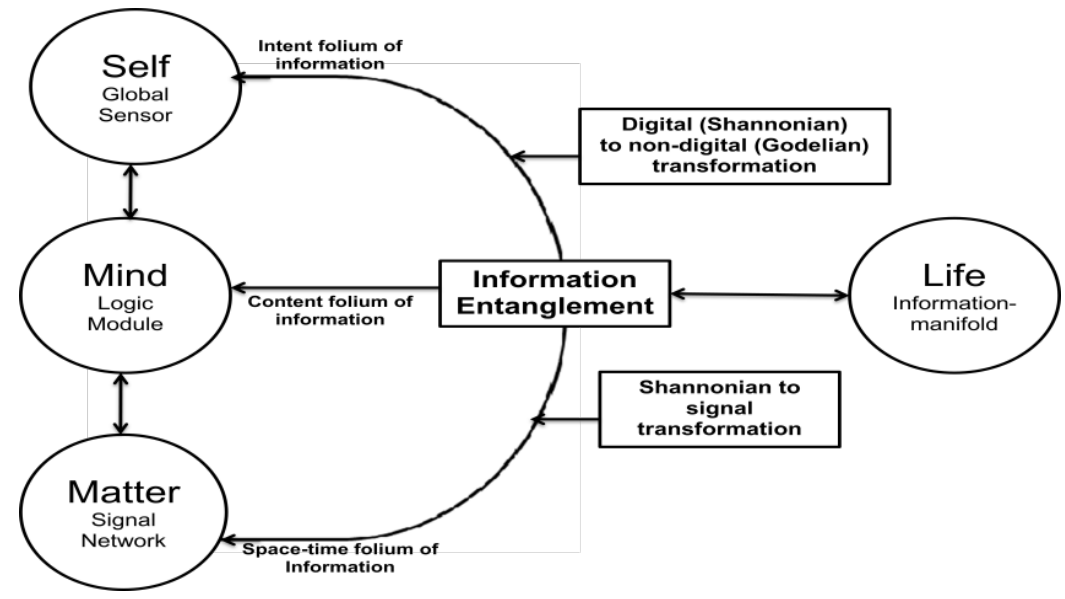

Figure 5: Information geometry and its entanglement spectrum. 


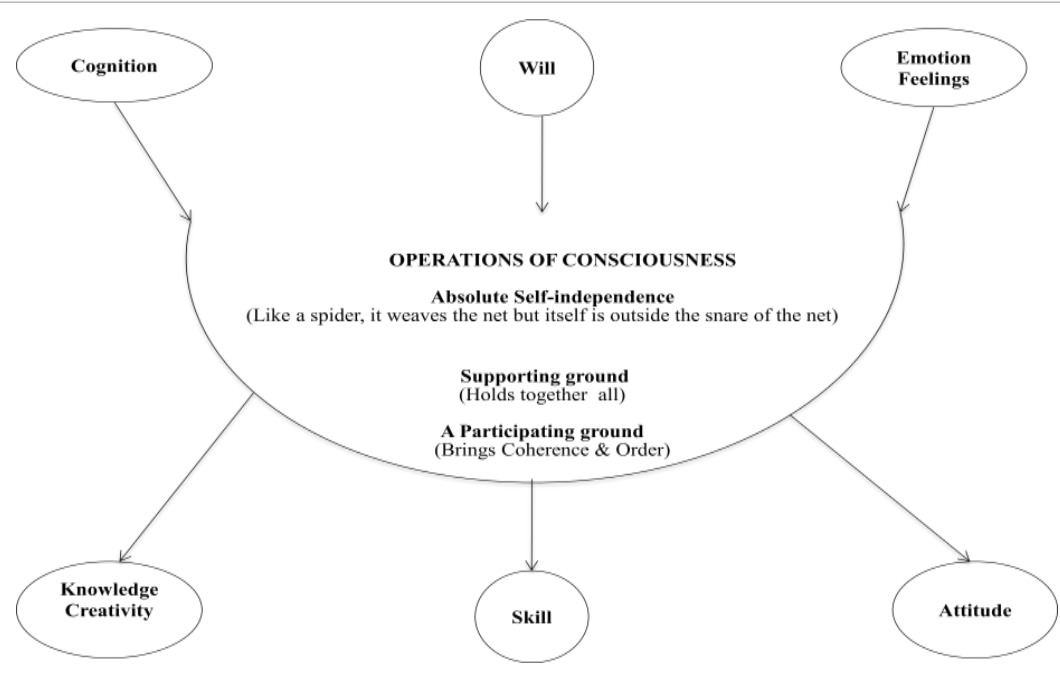

Figure 6: Operational mechanics of consciousness.

\begin{tabular}{|c|c|c|c|}
\hline S. No. & Categories of Intelligence & Operations involved \\
\hline 1. & Ordinary Intelligence & Mind, Self, Informational Memory \\
\hline 2. & Phenomenal intelligence & Mind, Self, Episodic Memory \\
\hline 3. & Emotional Intelligence & Mind, Self, Memory, Experience and Life \\
\hline 4. & Intuitive Intelligence & Consciousness, Self, Life, Mind, Memory and Experience \\
\hline
\end{tabular}

Table 1: Different kinds of Intelligence and their genesis.

The common sense response is, "wherever there is will, there is a way". The presence of will constructs the others. However, for the human being cognition is equally important. The knowledge is power and strength. Emotion is no less important either! Without emotion, there are no feelings! Bereft of any feelings we are zombie! In the spiritual context, Jnana-yoga is in the context of cognition, karma-yoga is in the context of will and bhakti-yoga is in the context of feelings.

How the systems become conscious of happening?: The system becomes conscious of any information, event and phenomenon by using one, two or all of the followings, through activity of mind, self or life. Mind cannot make the systems consciousness although it is at the centre of the spectrum stretching between consciousness and matter. The systems become conscious when there is break down of mind. Where mind ends consciousness begins. Self makes us consciousness when the intention-threshold of information does not match with concern-threshold of 'self and 'life' or with the perfection-threshold of the system as set by consciousness. 'Life' makes us conscious when there is disturbance in homeostasis of symmetry or the system encounters a new symmetry.

Signature of operation of consciousness: The signature of operational consciousness could be found in simultaneity of events, continuity of events and identity of events. Interestingly in the physical world, Einstein's constant excludes possibility of simultaneity of events, Planck's constant excludes possibility of continuity of events and entropy barrier excludes possibility of identity of events.

\section{Two more Interactive Mechanics of Different Constituents of the Psyche}

Many of the interactive mechanics have already been described. There are two more areas where this kind of interactive operations is much more complex; the Intelligence and the Emotion.

\section{The intelligence}

Intelligence emerges from the joint operations of self and mind, on the basis of past memory and experience. The landscape of intellect, however, is not limited to what has been said. When self and mind operate with informational memory, what emerges is ordinary intelligence, might be associative, combinatorial, but still ordinary and informational. When self and mind operate with episodic memory, which has a phenomenal origin, what emerges is phenomenal intelligence. When life too operates in creation of intelligence the expression gets an emotional overtone. Here output is disproportionately more than the input signal and is qualitatively different, strong and diffuse because of less 'mind', more conditioned 'self and strong life operations. We might call this emotional intelligence. When consciousness expresses itself through the triangular operation of self, life and mind, what emerges is intuitive intelligence. In other way of description, if ordinary intelligence is said dry intelligence and phenomenal intelligence the moist intelligence, emotional intelligence could be called juicy intelligence and intuitive intelligence, the crystal intelligence (Table 1) [16].

Intuitive intelligence is created by joint operation of consciousness, self, mind and life taking all kinds of experience and memory in the fold (Figure 7).

\section{The emotion}

Emotion has been said to be a functional operation of consciousness and is always bracketed with feelings. Neuroscience textbooks write that the feelings emerge out of emotional reactions. The alternate view is that emotional responses are the outcomes of feelings. This emotionfeelings debate on the primacy of one over the other has a way out if we accept that feelings is prerogative of self, while emotion is of 'life'. In a non-living entity, the question of emotional response does not arise! For the sake of argument in favor of panpsychism, one can say that 
even some inanimate object can feel but cannot express the feelings because of absence of 'life'.

Breakdown or loss of symmetry in the landscape of mind or selfinitiates a feeling and a life-operation for an emotional response. The feelings are expressed as emotion in live-situation. In emotional response, the output signal is diffuse and stronger than input signal. It may be qualitatively different too because of leakage through and amplification by life-operations. There is less of 'mind' but more of conditioned 'self in emotion. Conditioned self stresses on this alteration of symmetry with an emphasis. Since operations of mind are less active in emotion, receptivity and execution capacity of the subject is minimal in emotion (Figure 8).

\section{The Pathway from Signal to Will and Will to Signal: The Complete Model}

The pathways from will to signal, and back from signal to will is multilayered and labyrinthine with operators like consciousness, self, 'life', mind and information [17]. All are constituents of the psyche. Top down, it begins in consciousness and ends up in signaling. Bottom up, if one follows the pathway of transformation of signal, one would eventually land up in consciousness. No signal or even information has direct access to consciousness. It has to be transformed through the following labyrinthine process (Figure 9).

The figure nine is self-explanatory showing several triangular interactions between the operators, which are shown within the circles. In the labyrinth there is a world of wisdom, a world of self, and a world of nature; all are interconnected. The apex of the world of wisdom is

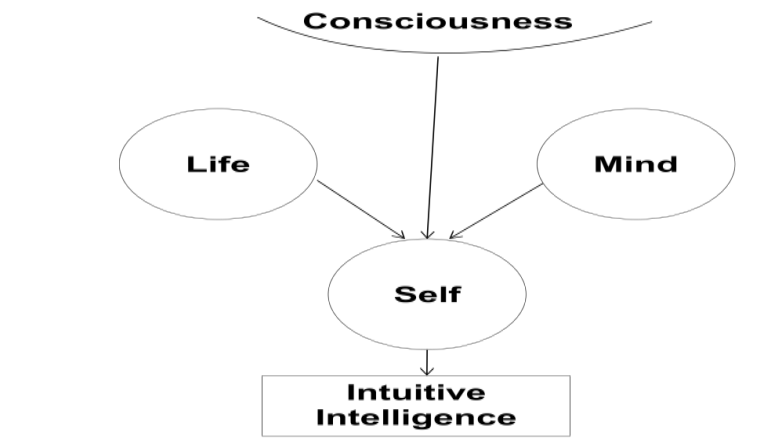

Figure 7: Origin of intuitive intelligence from joint action of consciousness, mind life and self.

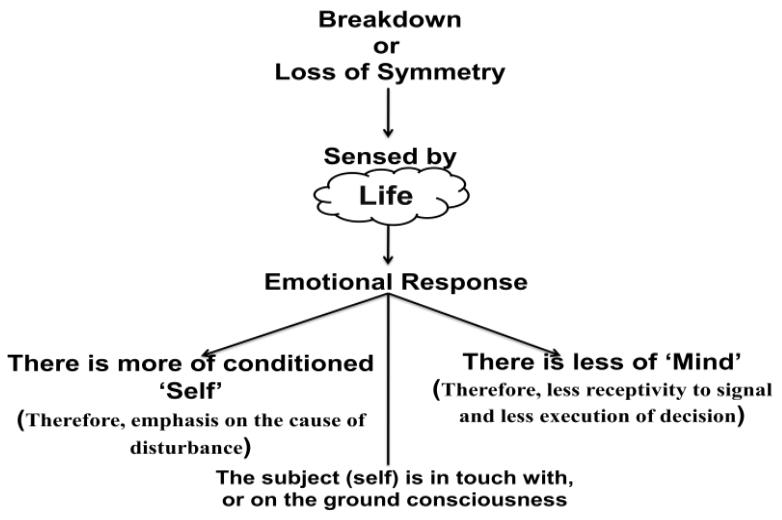

Figure 8: Origin and expression of emotion involving life, self and mind. open outside the labyrinth. This is the place of interaction of three 'alternate absolutes', world, self and God (wisdom).

The world of wisdom is in the awareness triangle, which is at the top, constituted by operations of consciousness, 'self and 'life'. Everawake 'self is in company of ever-present 'life'. A sleeping person becomes spontaneously awake because life-principle acts on the self. One falls asleep when life-principle loosely dissociates from 'self. The statements provoke us to look deeply into etiopathogenesis of several sleep disorders. We are reminded of the great saying, "God sleeps in the rock, dreams in the plant, stirs in the animal and awakens in man". (Inayat Arabe, 12th Century Sufi Mystic). The world of 'self with a sense of 'I', me and mine, is created by intelligence triangle which requires operations of mind, 'self' and experience/memory.

The nature-world is constituted by mind, information and life. Mind is sensitive to information and deals with information. The source of information is 'life'. Life-Information-Mind bears a triangular relationship and creates the nature world. All three of mind, 'self' and 'life' have direct connection with consciousness. However, consciousness, 'life' and 'self are in communication with matter only through mind. In this model consciousness-mind-matter forms the central axis of the psyche. The matter is also connected to mind through information (the right base of the Figure 9). This relationship is harnessed in computer programming. Matter is also related to self through memory and experience. Matter can retain memory and store experience. This relationship (left base of the Figure 9) is harnessed in creating intelligence in robot. The intelligence of a robot is nonintuitive. Intuitive intelligence to originate requires presence of element of 'life' and involvement of consciousness (Figure 7).

There is a demarcation between conscious subconscious and unconscious in this model. The triangular relationship at the top is responsible for wakefulness while two triangular relationships towards the bottom represent sub-conscious processing. The rectangle at the bottom is unconscious. The relationship between sub-consciousness and conscious processing as shown in the figure is of utmost importance for a healthy psyche.

In an analogy of panchakosha model of human body in Upanishad, the present model shows five nests of nature-consciousness. Classical physical laws and quantum physical principles respectively describe nests II \& I, the created nature, natura naturata. This is the nest of surface phenomenology. In the nest III there are operators like information, mind, intelligence and memory. This is the nest of elementary phenomenology. 'Self' and 'life' operate from nest IV, the natura naturans, and creative nature. This is the nest of depth phenomenology. Nest $\mathrm{V}$ is domain of unconditional consciousness.

Finally, the geometric symbols like point, circle, sphere, triangle, rectangle (representing matter) open circle/sphere, (representing consciousness) and a straight connecting line (consciousness-mindmatter axis) in a dynamic matrix in the 'wooly' sub-Planckian nature are the symbols used in various streams of complementary and alternative medicine (CAM) to represent the "causative element" in the universe and in the body. The model presented thus has the scope for opening up to CAM with contingent modification.

\section{The 'moment' and the 'point'}

While awake, the self-experiences the 'moment' when the mind makes 'point'. For example, the "image" of the psyche is a Moment in experience of self, while the model presented in this paper makes the Point by mind that is understandable to senses. The 'point' is, 


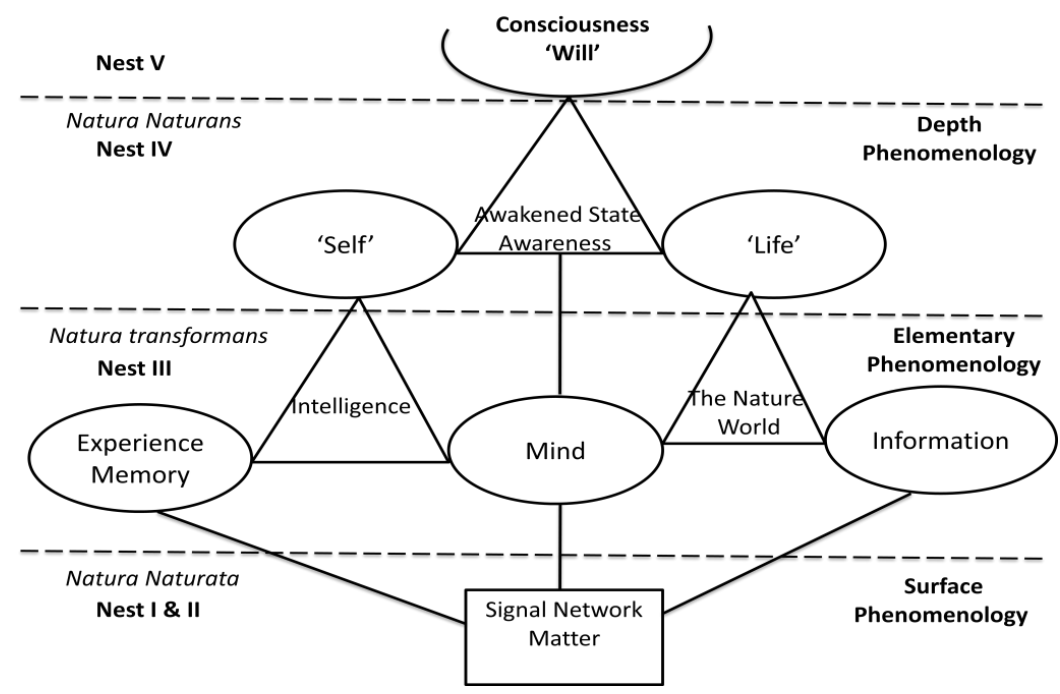

Figure 9: The pathway from will to signal and signal to will.

however, dead and the 'moment' is alive like bee in a beehive. From point to moment is a tortuous steep Ascent. From moment to point is an equally difficult Descent! Both ascent and descent cannot occur without cooperation from 'life' and consciousness. The mind deciphers information presented by the moment and constructs dimensions of complex space and time, amenable to senses! What the sensory cortex can identify are form and movement. The mind delivers space, time (and energy) from the conceived information.

\section{Event management by the psyche}

Events are observable in quantum and classical nests of nature. The origin of any event is in the 'will' by consciousness (nest V). Making a 'will' is always a prerogative of consciousness. The 'will' has a purpose executed by the operation of 'life' and 'self from nest IV. 'Life' creates requisite information and the 'self modulates the phenomena at elementary level (nest III). The event surfaces first at quantum level (nest II) and finally at classical level (nest I). This is the algorithm of how 'free will' runs on the Newtonian 'wheel' at the classical level!

\section{Primary Motivational Factors of the Psyche}

An important property of psyche is motivation. The origin of motivation is not in the mind, nor in 'life'. It is in 'self. Motivation arises from 'self's private facets. To understand this private facet of 'self, we are to examine the phenomena, elementary in nature, which participated during separation of self as system's executive from unconditional consciousness. The phenomena are, (i) a desire for creation, the expression of "sex", (ii) the birth of something new as a separate system, the expression of "Life", (iii) informational conditioning of the existence of the born system resulting in its "Ego", (iv) with a tendency in the system for sharing its property with other, an expression of "Love". The separation process is accompanied by (v) "Death" of the unity and homogeneity of original unconditional consciousness. The phenomena mentioned are absolutely elementary in nature. Any system supposed to have a 'self, cannot avoid, bypass or skip its influence. The elementary phenomenology (in nest III) is sandwiched between surface phenomenology of material (classical and quantum) world (nest II \& I) and depth phenomenology (nest IV) of self and life (Figure 9). Interestingly, the leaders in the field of psychology have emphasized on one or the other of these private facets of self in the psyche. Freudian school has laid emphasis on 'Sex', Alfred Adler on 'Ego', Jungian School on synchronicity, - a phenomenon seen in 'Love', Abraham Maslow on hierarchy of needs and fulfillment of 'Life'. Sri Aurobindo from India demonstrated meticulously in his epic work, Savitri, the steps for conscious physical conquest of 'Death' while alive. He has deliberated on the importance of self's molding through this process of death in individuation. The imprints of these five phenomena, namely Sex, Life, Ego, Love, and Death, therefore could always be identified on 'self. These imprints form self's private facets. The concept evolves as a synthesis of individual contributions from those who are recognized as the leading luminary of human psyche.

All motivations arise on stimulation of one or the other of the five private facets of self. The stimulation is either intrinsic or extrinsic with informational or phenomenal inputs. An organism or a being is motivated by a desire (sex), for survival (either-life-or-death situation), to de-condition and recondition its own existence (ego), and to share its properties with others (love). There is probably no other primary motivational factor known to us.

\section{Testability of the Proposition}

Science speaks in third person's perspective. Could the nonphysical existence of the operators and their operation be verified? The answer seems to be in affirmative. One might begin with Analysis of behavior of the subjects on the basis of proposed operations in terms of their incomplete development (e.g., in children and adolescents), operational deficit in adulthood as deficiency of any isolated or joint operation. A second source for testing the proposal is analysis of the experience of accomplished mystics and mystical philosophers who have been practicing inward Olympics with these operators within their own psyche. Absolutely third person's perspective could, however, be achieved if we can identify the footprints of the operators in the material plane of the brain at the molecular level and when we come close to the signature signal and signature molecule of specific operation.

\section{The psyche and the neurotransmitters}

The neurotransmitters in the brain have been classified according to size (small molecules and large molecules), according to whether 
the vesicle is electron-lucent or electron-dense, or according to their chemical nature like amine, amino acid, peptides, diffusible gas or something else [18]. Is it possible to classify those as material representative of the operation in the psyche? Living cell produces matters to carry out a defined purpose. Neurotransmitters could be understood from this top-down view as well. Following is a Table (Table 2), which relates operations of the constituent of the psyche with known neurotransmitters, citing at the third column of the table the circumstantial evidence and some other reasons for such suggestion (Table 2).

\section{Psyche of a cell}

The cell membrane has been doing inter-phasing between internal and external worlds of a cell. It acts as an organ of communication between two conscious systems. Therefore, the 'mind' is represented by cell membrane in the systems cell. As a computer chip is a crystal semiconductor with gates and channels so "the membrane is a liquid crystal semiconductor with gates and channel" [19]. The molecular gating mechanisms operating in the cell membrane could be related to operators of the psyche.

Ion channels are trans-membrane integral proteins that span through the whole thickness of the membrane. The opening and closing mechanism, that is gating, involves conformational change. There are several types of gating such as voltage gating, chemical gating (e.g. ligand-gating or by phosphorylation), and pressuregating through cytoskeleton [20]. Stimulus-Excitation coupling and Excitation-Contraction coupling within a cell are not mind-less activity. Biochemical representation of such mind action is reflected in $\mathrm{Na}^{+}-\mathrm{K}^{+}$ion channel in stimulus-excitation coupling and $\mathrm{Ca}^{++}$ion channel in excitation-contraction coupling. While ion channels are passive and require no energy for activity, ion-transporter requires energy from breakdown of ATP.

Ion channels and Ion-transporters across the cell membrane that could be considered for material representative of operation of constituents of psyche is shown in Table 2. Reasons for such suggestion with circumstantial evidence have been cited in the third vertical column of the table (Table 3 ).

Table 2 on neurotransmitter and Table 3 on cellular membrane molecules are very tentative. Both areas are fertile to generate further research in psychology, psychiatry and in therapy.

\section{Perspectives}

A beneficial spin-off from this model is a new way of classifying psychological and psychiatric disorders with added confirmation from clinical laboratory on the value of respective signature molecule or signature signal. There could be disorder of mind, disorder of infrastructure supporting the mind, disorder of information handling by mind, disorder of operation of self, disorder of operation of 'life', and disorder in operation of consciousness. There would be disorders resulting out of defective joint operations of the constituents. Disorder of will and skill could be a defective joint operation of consciousness self and mind; disorder of emotion and feelings a defective joint operation of consciousness and life; and disorder of intelligence could be a defective joint operation of self, mind and memory. Most of the disorders would have their respective signal or molecular footprints.

Another spin-off from this proposition could lead us to different approach in therapy. Cognitive therapy, being therapy, motivational therapy and pharmaceutical therapy require to be modified considerably on the basis of this proposed structure and operation in

\begin{tabular}{|c|c|c|}
\hline Operation of & Neurotransmitter & $\begin{array}{l}\text { Reasons for such suggestion } \\
\text { Circumstantial Evidence }\end{array}$ \\
\hline Life & $\begin{array}{l}\text { Acetyl choline } \\
\text { Histamine } \\
\text { Epinephrine } \\
\text { Norepinephrine etc. }\end{array}$ & $\begin{array}{l}\text { Most primitive neurotransmitters } \\
\text { Related to phenomena of arousal and awakening } \\
\text { Acetyl choline and Histamine are ubiquitous in nervous system }\end{array}$ \\
\hline Information & $\begin{array}{l}\text { Glutamate } \\
\text { Y-Amino butyric acid } \\
\text { Aspartate } \\
\\
\text { ATP } \\
\text { Adenosine } \\
\text { Nitric oxide } \\
\text { Glycine etc. }\end{array}$ & $\begin{array}{l}\text { Where neurons transmit only physical signals, glial participation is not essential. When neurons handle information, } \\
\text { co-operation from astrocytes is essential. The synapse there becomes tripartite } \\
\text { There are three well-defined metabolic shuttles between neurons and astrocytes in the cortex: Glutamate-glutamine } \\
\text { shuttle, malate-aspartate shuttle, lactate shuttle. They represent neuron-glia cooperation at biochemical level } \\
\text { Besides, Adenosine and ATP diffuse from astrocytes to neurons. So is the case for NO and glycine } \\
\text { In addition to nurturing neuron with lactate, the astrocyte is involved in conversion of non-informational metabolites } \\
\text { like glutamate, malate, glycine, adenosine and ADP into informational molecules as neurotransmitters }\end{array}$ \\
\hline Self & $\begin{array}{l}\text { Serotonin } \\
\text { ATP } \\
\text { Steroid etc. }\end{array}$ & $\begin{array}{l}\text { Serotonin is related to development of depression. Depression is a disease of disconnect of self from the environment } \\
\text { ATP maintains } \mathrm{Na}^{+} / \mathrm{K}^{+} \text {pump. Self's representation at biochemical level is this ion pump } \\
\text { Steroid therapy invokes a false sense of well being }\end{array}$ \\
\hline Mind & $\begin{array}{l}\text { Dopamine } \\
\text { Acetyl choline } \\
\text { Norepinephrine etc. }\end{array}$ & $\begin{array}{l}\text { Related to cognitive expression } \\
\text { Activities of enzymes, which are responsible for synthesis of these neurotransmitters reportedly decline with aging } \\
\text { Their activity is low in dementia (Alz. Dis.). There is loss of Ac.Ch. containing neurons in the basal nucleus of } \\
\text { Meynert in Alz. Dis. } \\
\text { Neurotransmitters in senior elderly who retain good cognitive function might offer more insights into the issue }\end{array}$ \\
\hline Consciousness & $\begin{array}{l}\text { Arachidonic acid } \\
\text { Prostaglandins (PGs, particularly } \\
\text { the volatile ones) etc. } \\
\text { Melatonin }\end{array}$ & $\begin{array}{l}\text { PGs and arachidonic acid are involved in, } \\
\text { Cerebral microcirculation (platelet-endothelial integrity) } \\
\text { Several hypothalamic homeostatic mechanisms } \\
\text { Protection of cortical neurons from glutamate toxicity } \\
\text { Perception of pain } \\
\text { Activities in neurons of forebrain and hippocampus } \\
\text { Melatonin is secretion of pineal gland, which has piezo-crystal sensor for different subtle signals. It is also called } \\
\text { "hormone of darkness" }\end{array}$ \\
\hline
\end{tabular}

Table 2: Operations of psyche and their probable relation to neurotransmitters. 
Citation: Mukhopadhyay AK (2016) Systems Psyche: Its Structure, Operation and Possible Molecular Links. Abnorm Behav Psychol 2: 121. doi: 10.4172/2472-0496.1000121

Page 10 of 10

\begin{tabular}{|c|c|c|}
\hline Operation of & $\begin{array}{l}\text { Ion Channels, Pumps and } \\
\text { Molecules }\end{array}$ & $\begin{array}{l}\text { Reasons for such suggestion. } \\
\text { Circumstantial Evidence }\end{array}$ \\
\hline Mind; immediate & Voltage-gated ion channel & $\begin{array}{l}\text { Stimulus-Excitation coupling and Excitation-Contraction coupling are not mindless operation } \\
\text { Biochemical representation of such mind action is reflected as } \mathrm{Na}^{+}-\mathrm{K}^{+} \text {ion channel in Stimulus-Excitation coupling, } \\
\text { and } \mathrm{Ca}^{++} \text {ion channel in Excitation-Contraction coupling }\end{array}$ \\
\hline Mind with Time & $\begin{array}{l}\text { Ligand-gated ion channel, } \\
\text { Phosphorylation-gated channel }\end{array}$ & Chemical gated channels require some time to become functional \\
\hline Self & $\begin{array}{l}\text { Ion-Pumps: } \\
\mathrm{Na}^{+}-\mathrm{K}^{+} \text {ion pump } \\
\mathrm{Ca}^{++}-\mathrm{H}^{+} \text {ion pump } \\
\\
\mathrm{MHC}-\mathrm{I} \text { molecules }\end{array}$ & $\begin{array}{l}\text { 'Self' of the cell actively maintains its ionic milieu and thus preserves its identity and differences from other cell } \\
\text { MHC-1 molecules distinguish self from non-self at cellular level }\end{array}$ \\
\hline 'Life' & Cytoskeleton-gated ion channel & $\begin{array}{l}\text { Cytoskeleton integrates all vital organelles of cell such as nucleus, mitochondria and lysosome with the cell } \\
\text { membrane, mechanically, spatio-temporally and informationally. Detachment of cytoskeleton from cell membrane } \\
\text { disturbs 'life' of a cell }\end{array}$ \\
\hline Consciousness & $\begin{array}{l}\text { Fas-receptor for activation of } \\
\text { caspase pathway for apoptosis. } \\
\text { Programmed cell Death (PD) } \\
\text { receptor for ligant- } 1 \& 2 \text { etc. }\end{array}$ & In making decision on death-signal for the cell, involvement of consciousness seems mandatory \\
\hline
\end{tabular}

Table 3: Operators of the psyche and the related gating and transport mechanisms of cell membrane.

one hand and its suggested molecular links on the other. The beneficial effects of CAM are likely to be harnessed with contingent modification of the model.

\section{Concluding Remarks}

The psyche is the dynamic determinant in individuation. For understanding abnormal and behavioral psychology and for restoring back such cases to normalcy, we desperately need a new model of psyche with expanded horizon accommodating recent developments in neuroscience, molecular biology, cellular cognition, and science of consciousness. The first objective of this paper was to develop such a model. The second objective was to incorporate the science of psyche within the systems science of biology in one hand and consciousness on the other. The readers are to judge whether we have achieved our stated objectives or not. It seems that the 'psyche' has been "cracked". It has been cracked into its essential fundamental elements. The fundamental elements have been re-aligned into a wonderful skyscraper, which is open at the top. The skyscraper has been described in a common universal language, which transcends culture and belief system. This kind of description is the characteristic of science. Moreover, the science is not to cling to any particular theory or a proposition. Rather, it is about questioning this. "The fundamental strength of science is that it compels its practitioners to confront their own fallibility...Science is not always right - very far from it. What marks it out from other fields of human endeavor is that, because of its formalized humility, it's always ready to correct itself when it makes a mistake" (Mike Taylor). Therefore, on this proposed model there is immense scope for further expansion with greater depths, wider horizons and higher reaches.

\section{Acknowledgement}

The manuscript has been discussed during its preparatory stage with Amritapreeti, a student of Psychology, Dr Tapasyapreeti, MBBS, academic resident in the Dept. of Laboratory Medicine, AlIMS, Dr. Gaurav Chhabra, MD, and Dr. Shyam Prakash, PhD, both Asst. Prof. in my Department, several resident doctors of the Department, Dr. Nasim Mansoori, PhD and Dr. Pooja Pallavi, PhD, and Rizwana Quadri, a senior PhD student in the department. Dr Sudip Dutta, MD, Asst. Prof. in the Department has carefully read the manuscript and given valuable suggestions. Mrs. Pooja Taneja has been the secretarial assistant. I acknowledge and thank them all.

\section{References}

1. Eccles JC (1994) How the self controls its brain. Berlin: Springer-Verlag

2. Shapiro JA (2007) Bacteria are small but not stupid: cognition, natural genetic engineering and socio-bacteriology. Stud Hist Philos Biol Biomed Sci 38: 807-819.
3. Pollan M (2006) The omnivore's dilemma: a natural history of four meals Penguin Press.

4. Pollan M (2002) The botany of desire: a plant's eye view of the world. New York: Random House Trade.

5. Penrose R (1999) The emperor's new mind. Oxford University Press.

6. Tegmark M (2014) Our mathematical universe. Random House.

7. Mukhopadhyay AK (1987) Psychology of a cell. In: The Dynamic web of Supracortical Consciousness. Conscious Publications. pp: 156-166.

8. Sekhar DMR (2011) Genopsych. A Coinage in the Foundry of Biology. Scientific Publishers.

9. Johnston H (2012) Can GPS find variations in Planck's constant?

10. Seshavatharam UVS, Lakshminarayana S (2013) Is Planck's constant a cosmological variable? International Journal of Astronomy 2: 11-15.

11. Mukhopadhyay AK (2013) Non-observable Influential(s) in the domain of consciousness. Psychology Research 3: 637-652.

12. Mukhopadhyay AK (2014) Life within the Akhanda Worldview. Dialogue and Universalism XXIV 2: 25-49.

13. Ganti T (2003) The principles of life. Oxford University Press.

14. Mukhopadhyay AK (2008) A radical view of information. On its Nature and Science. Frontier Perspective 16: 19-29.

15. Mukhopadhyay AK (2014) From quantum to consciousness. A long way to go In: Chopra D (ed.) The nature of our existence and the universe. California: Deepak Chopra. pp: 202-229.

16. Mukhopadhyay AK (2015) Neural fabrics of the mind: systems neuroscience, systems psychology and consciousness. Annals of Psychiatry and Mental Health 3: 1049-1068.

17. Mukhopadhyay AK (2015) Systems cell: a testable model for systems holism International Archives of Medicine 8: 1-10.

18. Schwartz JH, Javitch JA (2013) Neurotransmitters. In: Kandel ER, Schwartz JH, Jessell TM, Siegelbaum SA, Hudspeth AJ (eds.) Principles of Neural Sciences. New York: McGraw Hill. pp: 289-306.

19. Lipton BH (2008) The biology of belief. California: Hay House Inc

20. Siegelbaum SA, Koester J (2013) Ion Channels. In: Kandel ER, Schwartz JH Jessell TM, Siegelbaum SA, Hudspeth AJ (eds.) Principles of Neural Sciences. New York: McGraw Hill. pp: 100-125. 